\title{
Incidence, severity, and outcome of adverse events to chemotherapeutic drugs used in hematological malignancies: Data from a reference center
}

\author{
José C. Jaime-Pérez*, Gisela García-Arellano, Grecia A. Turrubiates-Hernández, José L. Herrera-Garza, \\ Luis J. Marfil-Rivera and David Gómez-Almaguer
}

Department of Hematology, Dr. José Eleuterio González University Hospital, School of Medicine of the Autonomous University of Nuevo Leon, Monterrey, Mexico

\begin{abstract}
Objective: The aim of the study was to document the frequency, severity, evolution, and impact of adverse events (AE) on chemotherapy and the clinical evolution of patients with hematologic malignancies. Material and Methods: A prospective study was carried out at a hematology reference center in Northeastern Mexico over 1 year. All patients with malignant disease developing adverse chemotherapy events were included in the study. AEs were classified according to Common Terminology Criteria for AEs v5.0. Results: One-hundred and seventy-four patients attended the hematology clinic for outpatient chemotherapy. Acute lymphoblastic leukemia accounted for 51.7\%, non-Hodgkin's lymphoma $25.9 \%$, acute myeloid leukemia 9.8\%, multiple myeloma 6.3\%, Hodgkin's lymphoma 5.7\%, and chronic myeloid leukemia $0.6 \%$ of the cases. A total of 191 AEs, including 79 hospital admissions, were registered in $58(33.3 \%)$ patients. About $62.3 \%$ of the cases were Grade 3 , in $43.9 \%$ of the events complete resolution was achieved, whereas the chemotherapy regimen had to be suspended in $13.6 \%$ of the cases. Febrile neutropenia was the main AE, documented in 77.6\%; four (6.9\%) patients died as a direct consequence of this complication. Thrombocytopenia occurred in $65.5 \%$ and anemia in $55.2 \%$, with no deaths. Conclusions: AEs secondary to chemotherapeutic drugs used in the treatment of hematological malignancies constitute an important cause of morbidity and occasional mortality and should be closely monitored and documented.
\end{abstract}

Key words: Adverse event. Hematologic malignancy. Acute leukemia. Lymphomas. Febrile neutropenia.

\section{Introduction}

Cancer is the second leading cause of mortality in the world, and almost 1 out of 6 deaths are due to cancer ${ }^{1}$. Hematological malignancies have a high incidence and mortality. In Mexico in 2014, hematological malignancies took thirteenth place in mortality, first in ages 5-9 and second in ages 10-142. The dictionary of the National Cancer Institute uses adverse effect and adverse event (AE) as interchangeable concepts, defined as an unexpected medical problem that happens during treatment with a drug or other therapy ${ }^{3}$. There is a wide variety of chemotherapeutic agents used in patients suffering hematologic cancer, and the AEs that occur during treatment with these drugs are common. In most cases, patients receive combined chemotherapy schemes, using multiple drugs, thus increasing the risk of toxicity and vulnerability to AEs. The discontinuation of treatment is sometimes necessary for the management of toxicity due to antineoplastic agents, directly

\section{Correspondence:}

*José C. Jaime-Pérez

E-mail: carjaime@ hotmail.com
Available online: 30-09-2019

Date of reception: 17-07-2019

Date of acceptance: 13-08-2019 DOI: 10.24875/RMU.19000107
Medicina Universitaria. 2019;21(3):92-99 www.medicinauniversitaria.org

(1) CC BY-NC-ND license (http://creativecommons.org/licenses/by-nc-nd/4.0/). 
impacting the quality of life and clinical evolution of these patients ${ }^{4}$. It is important to know the frequency with which AEs occur due to agents currently used in hematology and the treatment strategies for an adequate intervention and resolution. In this respect, pharmacovigilance relates to the detection, assessment, understanding, and prevention of AEs or any other medicine-related problem ${ }^{5}$; this concept has just been introduced in low-middle income countries ${ }^{6,7}$, and it has become of special importance in oncology due to the new drug therapies being tested and approved. Despite conducting an extensive search in the literature, we were not able to find reports on adverse chemotherapy events in hematology patients. This study is aimed to establish the incidence of AEs secondary to chemotherapy in patients with hematological malignancies and to determine its treatment and influence on clinical paths.

\section{Materials and methods}

This was a prospective observational study carried out at the Department of Hematology of the Universidad Autónoma de Nuevo León's, School of Medicine and Dr. José Eleuterio González University Hospital. For the purpose of this study, the term AE was used to include expected AEs secondary to the administration of chemotherapeutic agents. Patients of all ages and both sexes with a diagnosis of hematological malignancy who attended the outpatient clinic for ambulatory treatment and presented an adverse chemotherapy event were included to document the frequency, treatment, evolution, and impact on the chemotherapeutic regimen. Medical records were reviewed, and a database was built, which included demographic information, diagnosis, therapy regimen, and specific documentation of any $A E$ related to the drugs administered, its treatment and clinical outcome; changes in scheduling, composition, and/or intensity of the proposed chemotherapeutic scheme were also documented.

Treatment protocols and outcomes for malignant hematology diseases in our population have been published ${ }^{8-16}$. For diagnosis and classification of the severity of AEs pertinent to this study, the Common Terminology Criteria for AEs v5.017 were used. Patients with anemia and thrombocytopenia were included if they presented bleeding in the case of thrombocytopenia or anemic syndrome in the case of anemia, and/or those who required transfusion despite not presenting clinical manifestations. Evaluation after the management of AEs was classified as complete resolution, partial resolution, persistence, or death.
In the case of febrile neutropenia, complete resolution was defined as the complete absence of fever and total recovery of the neutrophil count after management. Partial recovery: the resolution of fever, without recovery of the neutrophil count; Persistence: the persistence of fever, without recovery of the neutrophil count. Death: the cause of death was directly related to the episode of fever and neutropenia.

In patients who presented thrombocytopenia, complete recovery was defined as the recovery of the platelet count and the absence of bleeding. Partial recovery: the absence of bleeding with the persistence of the platelet count below the lower limit of normal but with an increase in the numbers after the transfusion. Persistence: persistence of bleeding and a platelet count below the normal limit, with no increase in the post-transfusion count. Death: the cause of death was directly related to the presence of bleeding associated with thrombocytopenia.

In patients with anemia, complete recovery was defined as total recovery of hemoglobin levels and the absence of anemic syndrome. Partial recovery: the absence of anemic syndrome, with the persistence of the hemoglobin level below the lower limit of normal but with an increase after packed red blood cells transfusion. Persistence: persistence of the anemic syndrome and a hemoglobin figure below the limit of normality, with no increase after transfusion. Death: the cause of death was directly related to the presence of anemia.

For data analysis, the statistical package SPSS (IBM SPSS Statistics for Windows, Version 22.0. Armonk, NY: IBM Corp) was used; descriptive analysis was performed. Categorical data were reported as counts and percentages while continuous data were reported as means and standard deviations or medians and ranges. Informed consent was obtained from all individual participants included. The protocol was approved by the Ethics and Research Committee at the Institution.

\section{Results}

One-hundred and seventy-four patients attended the outpatient hematology clinic for ambulatory chemotherapy during the study period; $80(46 \%)$ females and 94 (54\%) males with a median age of 22.5 years (2-93). A total of $191 \mathrm{AEs}$ were reported in 58 (33.33\%) patients receiving treatment with antineoplastics, with an incidence of 3 (range 1-11) adverse chemotherapy events per patient; their median of age was 22 years (2-86); and a sum of 79 admissions was documented with a median of 1 (range 1-5) admission per patient. 
Table 1. Severity of 191 adverse events in 58 patients with hematological malignancy receiving chemotherapy over a year. There was a median of three events per patient

\begin{tabular}{|c|c|c|c|c|c|c|c|}
\hline \multirow[t]{2}{*}{ Adverse event } & \multirow{2}{*}{$\begin{array}{c}\text { Patient }^{\mathrm{a}} \\
\mathbf{n}(\%)\end{array}$} & \multirow{2}{*}{$\begin{array}{c}\text { Events } \\
\text { n (\%) }\end{array}$} & \multicolumn{5}{|c|}{ Severity n $(\%)^{b}$} \\
\hline & & & Grade 1 & Grade 2 & Grade 3 & Grade 4 & Grade 5 \\
\hline Febrile neutropenia & 45 (77.59) & $55(28.80)$ & 0 & 0 & $48(87.28)$ & $3(5.45)$ & $4(7.27)$ \\
\hline Thrombocytopenia & $38(65.51)$ & $44(23.03)$ & 0 & $21(47.70)$ & $23(52.30)$ & 0 & 0 \\
\hline Anemia & $32(55.17)$ & $38(19.90)$ & 0 & $2(5.26)$ & $34(89.48)$ & $2(5.26)$ & 0 \\
\hline Nausea & $12(20.69)$ & $12(6.29)$ & $9(75)$ & $3(25)$ & 0 & 0 & 0 \\
\hline Vomit & $11(18.97)$ & $11(5.76)$ & $7(63.64)$ & $4(36.36)$ & 0 & 0 & 0 \\
\hline Constipation & $5(8.62)$ & $5(2.62)$ & $1(20)$ & $2(40)$ & $2(40)$ & 0 & 0 \\
\hline Oral mucositis & $13(22.41)$ & $13(6.80)$ & $1(7.70)$ & $8(61.54)$ & $4(30.76)$ & 0 & 0 \\
\hline Anal and oral mucositis & $3(5.17)$ & $3(1.57)$ & 0 & $1(33.33)$ & $2(66.64)$ & 0 & 0 \\
\hline Tumor lysis syndrome & $1(1.72)$ & $1(0.52)$ & 0 & 0 & $1(100)$ & 0 & 0 \\
\hline Hepatic toxicity & $1(1.72)$ & $1(0.52)$ & 0 & 0 & $1(100)$ & 0 & 0 \\
\hline Exanthema & $2(3.45)$ & $2(1.05)$ & $1(50)$ & 0 & $1(50)$ & 0 & 0 \\
\hline Cytosine arabinoside syndrome & $1(1.72)$ & $1(0.52)$ & c & - & - & - & - \\
\hline Differentiation syndrome & $2(3.45)$ & $2(1.05)$ & 0 & 0 & $2(100)$ & 0 & 0 \\
\hline Headache & $3(5.17)$ & $3(1.57)$ & 0 & $3(100)$ & 0 & 0 & 0 \\
\hline
\end{tabular}

${ }^{a} \mathrm{~A}$ single patient can have more than one adverse chemotherapy event over time. ${ }^{\mathrm{b}}$ Severity according to common terminology criteria for adverse events (CTCAE) Version 5.0. (17). 'The classification of this adverse event is not specifically described in the CTCAE manual.

Out of the 58 patients in this group, 25 (43.1\%) were females and $33(56.9 \%)$ males, $(p=0.591)$. The frequency of hematological malignancy in descending order was documented as follows: acute lymphoblastic leukemia (ALL) (24, 41.4\%), acute myeloid leukemia (AML) (14, 24.1\%), non-Hodgkin's lymphoma (NHL) (13, $22.4 \%)$, multiple myeloma (4,6.9\%), and Hodgkin's lymphoma $(3,5.2 \%)$, no AE was reported in patients with chronic myeloid leukemia. The highest percentage of AEs (96, 50.26\%) and hospital admissions (41, 51.90\%) occurred in 24 pediatric patients ( $<16$ years), followed by 84 AEs and 33 hospital admissions in 30 adults (1664 years) and finally $11 \mathrm{AEs}$ and 5 hospital admissions in four geriatric patients ( $\geq 65$ years). Most of the patients were receiving chemotherapy alone $(n=48$, $82.8 \%), 10$ received a combination of chemotherapy, radiotherapy, and/or hematopoietic stem cell transplantation.

Out of the 58 patients who presented AEs, 16 (27.6\%) had one or more associated comorbidities, including arterial hypertension in five patients, type 2 diabetes mellitus in four, and kidney disease in four patients. Twelve (20.7\%) patients were receiving concomitant pharmacotherapy at the time of the admission, including antihypertensive drugs, insulin, and calcium channel antagonists.

Febrile neutropenia was the main $\mathrm{AE}$ reported with a total of 55 episodes (28.8\%) and with a Grade 3 severity in $87.3 \%$ of the cases. Two 6 -year-old patients with a diagnosis of ALL B, a 15-year-old patient with NHL, and a 52-year-old patient with AML, all females, died of sepsis as a direct consequence of this $A E$; the responsible agents in the first two were E. coli, corynebacterium spp. in the NHL patient, and in the fourth case, fungal pneumonia was suspected, with no specific agent identified.

Thrombocytopenia (23\%) followed in frequency, with $47.7 \%$ of events classified as Grade 2 and $52.3 \%$ as Grade 3. No deaths were directly associated with this event. Anemia ranked third in frequency (19.9\%); $89.5 \%$ of the episodes were classified as Grade 3, with no associated deaths. The rest of the AEs reported, their frequency and severity throughout the study are shown in table 1.

Medical management of febrile neutropenia was based on antibiotics, mainly third-generation cephalosporin and aminoglycosides; antifungal drugs were also used to cover frequent microorganisms and treatment was subsequently adapted to clinical evolution and results of cultures. Granulocyte-colony stimulating factor 
Table 2. Clinical evolution of 191 adverse events in 58 patients with hematological malignancy receiving chemotherapy

\begin{tabular}{|c|c|c|c|c|c|c|c|c|}
\hline \multirow[t]{2}{*}{ Adverse event } & \multirow{2}{*}{$\begin{array}{c}\text { Patients }^{\mathrm{a}} \\
\mathrm{n}(\%)\end{array}$} & \multirow{2}{*}{$\begin{array}{c}\text { Events } \\
\text { n (\%) }\end{array}$} & \multicolumn{4}{|c|}{ Clinical evolution } & \multicolumn{2}{|c|}{ Suspension of chemotherapy } \\
\hline & & & $\begin{array}{l}\text { Complete } \\
\text { resolution }\end{array}$ & $\begin{array}{l}\text { Partial } \\
\text { resolution }\end{array}$ & Persistence & Death & Yes & No \\
\hline Febrile neutropenia & 45 (77.59) & $55(28.80)$ & $19(34.54)$ & $30(54.54)$ & $2(3.63)$ & $4(7.29)$ & $15(27.27)$ & $40(72.73)$ \\
\hline Thrombocytopenia & $38(65.51)$ & $44(23.03)$ & $13(29.54)$ & $30(68.20)$ & $1(2.30)$ & 0 & $3(6.82)$ & 41 (93.18) \\
\hline Anemia & $32(55.17)$ & $38(19.90)$ & $5(13.15)$ & $25(65.80)$ & $8(21.05)$ & 0 & $2(5.28)$ & $36(94.72)$ \\
\hline Nausea & $12(20.69)$ & $12(6.29)$ & $12(100)$ & 0 & 0 & 0 & 0 & $12(100)$ \\
\hline Vomit & $11(18.97)$ & $11(5.76)$ & $11(100)$ & 0 & 0 & 0 & 0 & $11(100)$ \\
\hline Constipation & $5(8.62)$ & $5(2.62)$ & $5(100)$ & 0 & 0 & 0 & $1(20)$ & $4(80)$ \\
\hline Oral mucositis & $13(22.41)$ & $13(6.80)$ & $8(61.53)$ & $4(30.77)$ & $1(7.70)$ & 0 & 0 & $13(100)$ \\
\hline Anal and oral mucositis & $3(5.17)$ & $3(1.57)$ & $1(33.33)$ & $1(33.33)$ & $1(33.33)$ & 0 & 0 & $3(100)$ \\
\hline Tumor lysis syndrome & $1(1.72)$ & $1(0.52)$ & $1(100)$ & 0 & 0 & 0 & $1(100)$ & 0 \\
\hline Hepatic toxicity & $1(1.72)$ & $1(0.52)$ & 0 & $1(100)$ & 0 & 0 & $1(100)$ & 0 \\
\hline Exanthema & $2(3.45)$ & $2(1.05)$ & $3(100)$ & 0 & 0 & 0 & 0 & $2(100)$ \\
\hline $\begin{array}{l}\text { Cytosine arabinoside } \\
\text { syndrome }\end{array}$ & $1(1.72)$ & $1(0.52)$ & $1(100)$ & 0 & 0 & 0 & $1(100)$ & 0 \\
\hline $\begin{array}{l}\text { Differentiation } \\
\text { syndrome }\end{array}$ & $2(3.45)$ & $2(1.05)$ & $2(100)$ & 0 & 0 & 0 & $2(100)$ & 0 \\
\hline Headache & $3(5.17)$ & $3(1.57)$ & $3(100)$ & 0 & 0 & 0 & 0 & $3(100)$ \\
\hline
\end{tabular}

${ }^{a} A$ single patient can have more than one adverse chemotherapy event over time.

was administered in $12.7 \%$ of the febrile neutropenia cases. The treatment of patients who presented anemia and thrombocytopenia was supportive. Symptomatic patients (anemic syndrome or bleeding) received transfusion therapy with packed red blood cells and/or platelet concentrates, respectively. Patients without associated symptoms, with platelet and hemoglobin levels below the normal limit, were transfused assessing the patient's clinical situation and the risk of decompensation.

The management of oral mucositis was based on maintaining adequate hygiene, use of solutions in the form of mouth rinses, and pain management; anal mucositis management consisted of cleaning the injured area and evaluation of the lesions to detect any associated complication.

Nausea and vomiting, with a frequency of $6.29 \%$ and $5.76 \%$, respectively, were prevented and treated with ondansetron. Constipation, with a low frequency of presentation (Table 1), was managed with oral polyethylene glycol.

Tumor lysis syndrome was reported on one patient. Its treatment consisted of the administration of intravenous fluids as well as the use of allopurinol. Similarly, liver toxicity was reported on one occasion. Its treatment was supportive, associated with the immediate suspension of the chemotherapeutic regimen.

Allergic reactions, manifested as exanthema, had a low frequency with two episodes. Administration of hydrocortisone and chlorpheniramine solved both cases. One case of cytarabine syndrome was reported, which was treated with hydrocortisone and immediate suspension of the drug, although there are no guidelines regarding this complication, a recent case report suggests using corticosteroids as premedication ${ }^{18}$. Differentiation syndrome was documented in two acute promyelocytic leukemia patients. Its treatment consisted of the immediate suspension of the drug as well as administration of dexamethasone ${ }^{19}$. The evolution of AEs events is shown in table 2. The chemotherapeutic scheme was suspended in $26(13.61 \%)$ of the 191 AEs, mainly due to febrile neutropenia (Table 2). Due to their relevance and high prevalence, table 3 and table 4 provide a description of the clinical and laboratory characteristics observed in the three most frequent $\mathrm{AES}$ 
Table 3. Clinical characteristics associated with febrile neutropenia, thrombocytopenia, and anemia in 58 hematological patients

\begin{tabular}{|c|c|c|c|c|c|}
\hline & Febrile neutropenia & \multicolumn{2}{|c|}{ Thrombocytopenia } & \multicolumn{2}{|c|}{ Anemia } \\
\hline Events & 55 & \multicolumn{2}{|l|}{44} & \multicolumn{2}{|c|}{38} \\
\hline Patients & 45 & \multicolumn{2}{|l|}{38} & \multicolumn{2}{|c|}{32} \\
\hline Events per patient [median (range)] & $1(1-4)$ & \multicolumn{2}{|l|}{$1(1-3)$} & \multicolumn{2}{|c|}{$1(1-2)$} \\
\hline $\begin{array}{l}\text { Sex } \\
\text { Female } \\
\text { Male }\end{array}$ & $\begin{array}{l}20(44.44) \\
25(55.56)\end{array}$ & \multicolumn{2}{|l|}{$\begin{array}{l}19(50) \\
19(50)\end{array}$} & \multicolumn{2}{|c|}{$\begin{array}{l}15(46.88) \\
17(53.12)\end{array}$} \\
\hline $\begin{array}{l}\text { Hematological diagnosis } \\
\text { ALL B } \\
\text { AML } \\
\text { NHL } \\
\text { HL } \\
\text { MM } \\
\text { ALL T }\end{array}$ & $\begin{array}{c}19(42.22) \\
11(24.44) \\
9(20) \\
3(6.68) \\
2(4.44) \\
1(2.22)\end{array}$ & \multicolumn{2}{|c|}{$\begin{array}{c}17(44.74) \\
12(31.58) \\
5(13.16) \\
1(2.63) \\
2(5.26) \\
1(2.63)\end{array}$} & \multicolumn{2}{|c|}{$\begin{array}{c}11(34.38) \\
12(37.50) \\
7(21.88) \\
0 \\
1(3.12) \\
1(3.12)\end{array}$} \\
\hline Infectious focus ${ }^{a}$ & & \multicolumn{2}{|l|}{ Bleeding } & \multicolumn{2}{|c|}{ Anemic syndrome } \\
\hline Absent & $25(45.45)$ & Absent & $14(31.80)$ & Absent & $5(13.15)$ \\
\hline Present & $30(54.55)$ & Present & $30(68.20)$ & Present & $33(86.85)$ \\
\hline Pulmonary & $15(27.30)$ & Epistaxis & $11(25)$ & & \\
\hline Gastrointestinal & $3(5.45)$ & Gingivorrhagia & $10(22.72)$ & & \\
\hline Soft tissue abscess & $6(10.90)$ & Hematuria & $3(6.81)$ & & \\
\hline Sepsis & $5(9.10)$ & Purpuric syndrome & $3(6.81)$ & & \\
\hline Herpetic stomatitis & $3(5.45)$ & Digestive tract bleeding & $1(2.27)$ & & \\
\hline Sinusitis & $1(1.81)$ & Metrorrhagia & $2(4.54)$ & & \\
\hline Osteomyelitis & $1(1.81)$ & Hemoptysis & $1(2.27)$ & & \\
\hline Phlebitis & $1(1.81)$ & \multicolumn{2}{|c|}{ Transfusion therapy } & \multicolumn{2}{|c|}{ Transfusion therapy } \\
\hline \multirow[t]{2}{*}{ Associated death } & $4(6.9)$ & Yes & $40(90.90)$ & Yes & $38(100)$ \\
\hline & & No & $4(9.10)$ & No & 0 \\
\hline
\end{tabular}

a One single patient can have more than one infectious focus. ALL B: acute lymphoblastic leukemia type B; AML: acute myeloid leukemia; NHL: non-Hodgkin's lymphoma; HL: Hodgkin's lymphoma. MM: multiple myeloma; ALL T: T-cell acute lymphoblastic leukemia. G-CSF: granulocyte-colony stimulating factor.

found in our hematology population, febrile neutropenia, thrombocytopenia, and anemia. Importantly, no clerical errors were documented in the administration of chemotherapy drugs during the period of the study.

\section{Discussion}

To the best of our knowledge, this is the first prospective study exclusively aimed at identifying AEs in hematology patients with a diagnosis of malignant disease who are receiving chemotherapy and documenting its treatment and clinical outcome; hematology population is frequently included among malignancies in general ${ }^{20}$ and even specifically excluded from other AE studies ${ }^{21}$. Although chemotherapeutic agents are highly cytotoxic, only one-third of our population presented an $\mathrm{AE}$. This can reflect good safety practices for drug administration and the effectiveness of prophylaxis available for expected AEs. The AEs found in our patients with hematological malignancies constituted an important cause of morbidity. Chemotherapy-based treatment is critical for this group of diseases; however, given the disease complexity, most patients receive multidrug regimens. Therefore, the risk of toxicity and AEs is high, and it is difficult to assign the cause to a single drug. In addition to affecting quality of life, AEs influence the clinical evolution of the disease due to the AE itself or the need for delay, reduction of doses, or even suspension of the chemotherapy regimen ${ }^{4}$. 
Table 4. Laboratory characteristics associated with febrile neutropenia, thrombocytopenia, and anemia in 58 hematological patients

\begin{tabular}{|l|c|c|c|c|c|}
\hline \multicolumn{1}{|c|}{ Febrile neutropenia } & \multicolumn{2}{|c|}{ Thrombocytopenia } & \multicolumn{2}{c|}{ Anemia } \\
\hline Leukocytes* $^{*}$ & $1.06 \pm 1.11$ & Platelets* & $12.39 \pm 13.64$ & Hemoglobin & $6.17 \pm 1.14$ \\
\hline Neutrophils* & $0.107 \pm 0.153$ & & & & \\
\hline G-CSF use & $7(12.72)$ & & & & $8.54 \pm 2.07$ \\
\hline ANC post G-CSF & $1.88 \pm 2.24$ & PC post PT & $33.88 \pm 22.54$ & Hb post PRBC & \\
\hline
\end{tabular}

*(mean $\pm \mathrm{SD}) \mathrm{k} / \mu \mathrm{L},{ }^{5}(\mathrm{mean} \pm \mathrm{SD}) \mathrm{g} / \mathrm{dL}$. G-CSF: granulocyte-colony stimulating factor; ANC post-G-CSF: absolute neutrophil count after G-CSF administration; PC post-PT: platelet count after platelet transfusion; Hb post-PRBC: hemoglobin after packed red blood cell transfusion; SD: standard deviation.

In more than one-third of AEs hospital admission was required, some patients were admitted repeatedly, and some had more than one AE throughout the study period. Only in $17(8.9 \%)$ out of the 191 episodes presented, there was no improvement after treatment, whereas in $26(13.6 \%)$ cases chemotherapy had to be suspended. This shows the impact that these complications can have on the patients' quality of life, the chance of cure, and the potential danger that they represent.

Febrile neutropenia, thrombocytopenia, and anemia were the most common AEs found in our population, similar to results from solid tumor populations ${ }^{20-22}$. Treatment of the AEs relied on international guidelines ${ }^{23-25}$, personalized decisions based on an individualized approach of the patient, and the clinical judgment of the physician. In our study, more than $50 \%$ of AEs did not have complete recovery. It was necessary to suspend chemotherapy in $27 \%$ of the cases, and the four deaths reported were directly related to this complication; their successful treatment requires early recognition and therapy. Thus, the education of the patient and his/her family to recognize signs and symptoms of neutropenia at an early stage is an essential part of early treatment and therefore, of prevention of fatal outcomes. Anemia and thrombocytopenia frequently follow febrile neutropenia as AEs associated with chemotherapy. There are no guidelines on the appropriate management of patients with chemotherapy-induced thrombocytopenia and management consists of supportive treatment, based on delay or dose modification chemotherapy, and platelet transfusion for severe thrombocytopenia ${ }^{4,26-28}$, although the platelet count at which the transfusion should be given in these circumstances is not established, available literature suggests $20,000 / \mu \mathrm{L}^{28}$. Treatment of chemotherapy-induced anemia was also supportive, based on transfusion therapy according to hemoglobin levels and the patients' clinical situation. Recent guides recommend the use of erythropoiesis-stimulating agents, iron preparations, or red blood cell transfusions depending on the needs of each patient ${ }^{29,30}$.

Despite transfusion therapy, platelets and hemoglobin reached normal values in only $13.1 \%$ and $29.5 \%$ of our cases of thrombocytopenia and anemia, respectively; this was probably due to persistence of chemotherapy myelosuppressive effects and platelet consumption in the presence of fever and infection; therefore, it is important for the physician to adhere to transfusion guidelines strictly.

Although nausea and vomiting not being that common, an important consequence is that they could be associated with malnutrition ${ }^{4}$ and treatment adherence could also be affected. In our center, the prophylaxis and management of these events are given with ondansetron; guidelines also suggest dexamethasone and olanzapine, depending on the anti-neoplastic agent of greatest emetic risk included in the chemotherapy scheme $^{31,32}$.

Constipation was rare and was managed with an osmotic laxative, the first-line therapy in these cases, which resulted in resolution in all episodes ${ }^{33}$. The rest of the AEs secondary to chemotherapy observed in our population had a much lower frequency; however, they negatively affected the patient's quality of life and could be a cause of temporary suspension of the treatment. More than one in four of our patients had associated comorbidities, and one in five received concomitant pharmacological treatment. This could lead to interactions that may cause a decrease in treatment efficacy and an increase in the risk of presenting an $\mathrm{AE}^{34}$.

An important aspect of underscoring is the skills, experience, and training of the nursing personnel since they are responsible for the correct administration of chemotherapy schemes. A recent study demonstrated that the implementation of medication safety practices decreased the incidence of AEs related to chemotherapy 
in pediatric patients with $\mathrm{ALL}^{35}$. Our nursing personnel has 20 years of experience and certified training in hematological oncology, which may have positively influenced our results. Specific training for nurses is recommended to reduce the risk of presenting $\mathrm{AEs}^{35}$.

The lack of preventive guidelines regarding some of the $\mathrm{AEs}$, and the inadequate implementation of the existing ones may contribute to the incidence found in this report, besides a number of these events may be under registered. The reporting of AEs by treatment cycle and the use of patient-reported outcomes on the evaluation of anticancer drugs have been proposed to improve their safety, collection, and analysis ${ }^{36}$.

\section{Conclusions}

From these results, some conclusions can be reached: attention should be paid to the correct application of existing treatment guidelines for AEs. Training of health personnel is crucial to reduce AEs it is critical, to educate hematology patients and family members about the risks and possible complications associated with the chemotherapy scheme, their treatment, and situations in which a visit to the hospital is required. The health personnel must perform intentional questioning in search of associated AEs, which sometimes do not directly threaten the patient's life but cause deterioration in the quality of life and can interfere with the chemotherapy scheme. Additional AE studies and improved therapeutic strategies for neutropenic fever in hematology patients are needed.

\section{Funding}

This research did not receive any grant from funding agencies in the public, commercial, or not-for-profit sectors.

\section{Conflicts of interest}

The authors of this paper have no conflicts of interest, including specific financial interests, relationships, and/or affiliations relevant to the subject matter or materials included.

\section{Acknowledgments}

We thank Sergio Lozano-Rodriguez, MD, for his critical review of the manuscript.

\section{Ethical disclosures}

Protection of human and animal subjects. The authors declare that no experiments were performed on humans or animals for this study.

Confidentiality of data. The authors declare that they have followed the protocols of their work center on the publication of patient data.

Right to privacy and informed consent. The authors have obtained the written informed consent of the patients or subjects mentioned in the article. The corresponding author is in possession of this document.

\section{References}

1. World Health Organization Cancer. Key Facts; c2018. Available from http://www.who.int/news-room/fact-sheets/detail/cancer. [Last accessed on 2018 Aug 30].

2. Sormani MP, Muraro PA, Schiavetti I, Signori A, Laroni A, Saccardi R, et al. Autologous hematopoietic stem cell transplantation in multiple sclerosis: a meta-analysis. Neurology. 2017;88:2115-22.

3. National Institutes of Health NCl Dictionary for Cancer Terms. Available from: https://www.cancer.gov/publications/dictionaries/cancer-terms/def/ adverse-effect. [Last accessed on 2018 Aug 30].

4. Livshits Z, Rao RB, Smith SW. An approach to chemotherapy-associated toxicity. Emerg Med Clin North Am. 2014;32:167-203.

5. World Health Organization. Pharmacovigilance: ensuring the Safe Use of Medicines: WHO Headquarters in Geneva; c2004. Available from: http:// www.apps.who.int/medicinedocs/es/d/Js6164e/1.html. [Last accessed on 2018 Aug 30].

6. Arulmani R, Rajendran SD, Suresh $B$. Adverse drug reaction monitoring in a secondary care hospital in south india. Br J Clin Pharmacol. 2008;65:210-6.

7. Holtz L, Cecilio L, Minowa E, Julian G. Pharmacovigilance in oncology: knowledge and perception on adverse events reporting in Brazil. Value Health. 2015;18:A815.

8. Jaime-Perez JC, Lopez-Razo ON, Garcia-Arellano G, Pinzon-Uresti MA Jimenez-Castillo RA, Gonzalez-Llano O, et al. Results of treating childhood acute lymphoblastic leukemia in a low-middle income country: 10 year experience in Northeast Mexico. Arch Med Res. 2016;47:668-76.

9. Jaime-Pérez JC, Jiménez-Castillo RA, Pinzón-Uresti MA, Cantú-Rodríguez OG, Herrera-Garza JL, Marfil-Rivera LJ, et al. Real-world outcomes of treatment for acute lymphoblastic leukemia during adolescence in a financially restricted environment: results at a single center in Latin America. Pediatr Blood Cancer. 2017;64:26396.

10. Jaime-Pérez JC, Jiménez-Castillo RA, Herrera-Garza JL, Gutiérrez-Aguirre H, Marfil-Rivera LJ, Gómez-Almaguer D, et al. Survival rates of adults with acute lymphoblastic leukemia in a low-income population: a decade of experience at a single institution in Mexico. Clin Lymphoma Myeloma Leuk. 2017;17:60-8.

11. Jaime-Pérez JC, Gamboa-Alonso CM, Vázquez-Mellado de Larracoechea $A$, Rodríguez-Martínez M, Gutiérrez-Aguirre CH, Marfil-Rivera LJ, et al. Non-hodgkin lymphomas: impact of rituximab on overall survival of patients with diffuse large B-cell and follicular lymphoma. Arch Med Res. 2015;46:454-61.

12. Jaime-Pérez JC, Padilla-Medina JR, Salazar-Cavazos L, Fernández LT, Gómez-Almaguer D. Treatment of diffuse large B-cell lymphoma with and without anthracyclines and rituximab in patients older than 60 years: 10 year results at a Latin American center. Hematol Oncol. 2019;37:226-9.

13. Jaime-Pérez JC, Gamboa-Alonso CM, Padilla-Medina JR, Jiménez-Castillo RA, Olguín-Ramírez LA, Gutiérrez-Aguirre $\mathrm{CH}$, et al. High frequency of primary refractory disease and low progression-free survival rate of hodgkin's lymphoma: a decade of experience in a Latin American center. Rev Bras Hematol Hemoter. 2017;39:325-30.

14. Tarín-Arzaga L, Arredondo-Campos D, Martínez-Pacheco V, Martínez-González O, Ramírez-López A, Gómez-De León A, et al. Impact of the affordability of novel agents in patients with multiple myeloma: real-world data of current clinical practice in mexico. Cancer. 2018;124:1946-53.

15. Jaime-Pérez JC, Brito-Ramirez AS, Pinzon-Uresti MA, Gutiérrez-Aguirre H, Cantú-Rodríguez OG, Herrera-Garza JL, et al. Characteristics and clinical evolution of patients with acute myeloblastic leukemia in northeast Mexico: an eight-year experience at a university hospital. Acta Haematol. 2014;132:144-51.

16. Cantú-Rodríguez OG Sánchez-Cárdenas $\mathrm{M}$, Gutiérrez-Aguirre $\mathrm{CH}$, Jaime-Pérez JC, Mancias-Guerra C, González-Llano O, et al. Cultural factors related to adherence to imatinib in CML: a Mexican perspective. Hematology. 2015;20:72-6. 
17. National Institutes of Health. Common Terminology Criteria for Adverse Events (CTCAE) Version 5.0; c2017. Available from: https://www.ctep. cancer.gov/protocolDevelopment/electronic_applications/docs/CTCAE_ v5 Quick Reference 8.5x11.pdf. [Last accessed on 2018 Aug 30].

18. Jirasek MA, Herrington JD. Cytarabine syndrome despite corticosteroid premedication in an adult undergoing induction treatment for acute myelogenous leukemia. J Oncol Pharm Pract. 2016;22:795-800.

19. National Comprehensive Cancer Network NCCN Guidelines Acute MyeIoid Leukemia Version 2.2014; c2014. Available from: http://www.williams.medicine.wisc.edu/aml.pdf. [Last accessed on 2018 Sep 07].

20. Kaur K, Sood M, Bhagat S, Singh T, Jain M, Arora D, et al. Spontaneous adverse drug reaction monitoring in oncology: our experience. Indian J Cancer. 2015;52:467-70.

21. Buendía Bravo S, González Haba Peña E, García Sánchez R, Arrabal Durán $\mathrm{P}$, Sánchez Fresneda MN, Sanjurjo Sáez M, et al. Causes of the emergency department visits in cancer patients: postchemotherapy toxicity. Farm Hosp. 2015;39:333-7.

22. Lau PM, Stewart K, Dooley M. The ten most common adverse drug reactions (ADRs) in oncology patients: do they matter to you? Support Care Cancer. 2004;12:626-33.

23. Bennett CL, Djulbegovic B, Norris LB, Armitage JO. Colony-stimulating factors for febrile neutropenia during cancer therapy. N Engl J Med. 2013;368:1131-9.

24. Klastersky J, de Naurois J, Rolston K, Rapoport B, Maschmeyer G, Aapro M, et al. Management of febrile neutropaenia: esmo clinical practice guidelines. Ann Oncol. 2016;27:v111-8.

25. Taplitz RA, Kennedy EB, Bow EJ, Crews J, Gleason C, Hawley DK, et al. Outpatient management of fever and neutropenia in adults treated for malignancy: American society of clinical oncology and infectious diseases society of America clinical practice guideline update. J Clin Oncol. 2018;36:1443-53.

26. Kuter DJ. Managing thrombocytopenia associated with cancer chemotherapy. Oncology (Williston Park). 2015;29:282-94
27. Parameswaran $R$, Lunning $M$, Mantha $S$, Devlin $S$, Hamilton $A$, Schwartz G, et al. Romiplostim for management of chemotherapy-induced thrombocytopenia. Support Care Cancer. 2014;22:1217-22.

28. Vadhan-Raj S. Management of chemotherapy-induced thrombocytopenia: current status of thrombopoietic agents. Semin Hematol. 2009; 46:S26-32.

29. Aapro M, Beguin $\mathrm{Y}$, Bokemeyer C, Dicato M, Gascón P, Glaspy J, et al. Management of anaemia and iron deficiency in patients with cancer: esmo clinical practice guidelines. Ann Oncol. 2018;29:iv96-110.

30. National Comprehensive Cancer Network NCCN Guidelines Cancer and chemotherapy induced anemia Version 3.2018; c2018. Available from: https://www.nccn.org/professionals/physician_gls/pdf/anemia.pdf. [Last accessed on 2018 Sep 07].

31. Hesketh PJ, Kris MG, Basch E, Bohlke K, Barbour SY, Clark-Snow RA, et al. Antiemetics: American society of clinical oncology clinical practice guideline update. J Clin Oncol. 2017;35:3240-61.

32. National Comprehensive Cancer Network NCCN Guidelines Antiemesis, Version 2.2017; c2017. Available from: https://www.nccn.org/professionals/physician gls/pdf/antiemesis.pdf.

33. Larkin PJ, Cherny NI, La Carpia D, Guglielmo M, Ostgathe C, Scotté $\mathrm{F}$, et al. Diagnosis, assessment and management of constipation in advanced cancer: esmo clinical practice guidelines. Ann Oncol. 2018; 29:iv111-25.

34. Baldo P, Fornasier G, Ciolfi L, Sartor I, Francescon S. Pharmacovigilance in oncology. Int J Clin Pharm. 2018;40:832-41.

35. Mulatsih S, Dwiprahasto I, Sutaryo. Implementation of medication safety practice in childhood acute lymphoblastic leukemia treatment. Asian Pac J Cancer Prev. 2018;19:1251-7.

36. Flores B, Klaar S, O'Connor DJ. Changing views on adverse event reporting. Lancet Haematol. 2018;5:e506-7. 